\title{
Design Optimization and Manufacturing of shoulder fillet in Waveguide LR 260 Upper of Transmission System for Stress Concentration: Case Study in VTPL industry, Mumbai
}

\author{
Arjun. A. Abhyankar ${ }^{\# 1}$, Vinit Raut ${ }^{* 2}$, G .P. Deshmukh ${ }^{\# 3}$ \\ \# Department of Mechanical Engineering, Pune University \\ D.Y Patil institute of engineering and Technology, Ambi, Pune, India \\ ${ }^{1}$ arjun.abhyankar@yahoo.com \\ 3 gaurav.deshmukh@dyptc.edu.in \\ * vijay transtech, Mumbai \\ mahape MIDC,mumbai,India \\ 2 vinit.raut@rediffmail.com
}

\begin{abstract}
In this paper frequent failure of a Waveguide LR Upper 260 Transmission member employed in a VFD Motor is studied. Considering the Transmission system, forces and the torques acting on the shaft, Maximum stresses occurring at the failure section are determined. Optimal Notch geometry is obtained for Shaft subject to bending \& torsion loading condition. Geometrical features such as notches and corner give increases stress concentrations effect. Notches make localized stress concentration effects that can affect various failure mechanisms, in particular the initiation and expansion of small cracks under fatigue loads, considerably reducing the strength of Transmission components. For obtaining useful variable-radius notches, Mattheck Method is used to Reducing Von-mises stress, Max shear stress and Stress concentration by converting constant radius notch into variable radius notch. . Natural structural members, such as tree bones and branches, after million years of development have learned to utilize variable tip radii as an alternative of the fixed radius. Our results show that stress concentration factors, von misses stress and Max shear stress are effectively reduced by variable radius notch. From components manufacturing point of view, CNC Program is generated for Variable radius notch by using Master cam-x4.
\end{abstract}

Keyword - Notch Optimization, Waveguide LR Upper 260, Stress concentration, Mattheck Method, Variable radius notches, Master cam X4

\section{INTRODUCTION}

A shaft is a rotating member, typically of circular cross-section for transmitting power. It is supported by bearings \& supports gear, sprockets, wheels as well as rotors. It is subjected to torsion, or bending loads, acting in single or in combination. Usually shafts are not of regular diameter but are stepped to provide shoulders for locating gears, pulleys and bearings, [14]. In this case study, Waveguide LR Upper 260 Transmission member employed in a VFD Motor is studied. Optimal Notch geometry is obtained for Shaft subject to bending \& torsion loading condition. Notches are typically required for operational, structural, or industrialized reasons, or else to reduce weight, so they are in fact a practical require. However, if not correctly designed they can much trouble the local stress and strain field around them, locally rising or concentrating the nominal stresses. Such localized stress concentration effects depend on the notch geometry and on the loading environment, and can much reduce the real component strength.

A material independent stress concentration factor (SCF) defined by

$$
k t=\frac{\sigma \max }{\sigma \text { nom }}
$$

Where; $\sigma$ max is the maximum stress acting at the notch and $\sigma$ nom is the nominal stresses that would act there if the notch had no effect on the stress field that surroundings it. The aim of this study is first to compare the efficiency of both constant radius and variable radius for design better notch profiles, and then to analyze the SCF improvement attainable by optimizing the variable radii of notches for torsion and bending load applications, using the FEA method. 


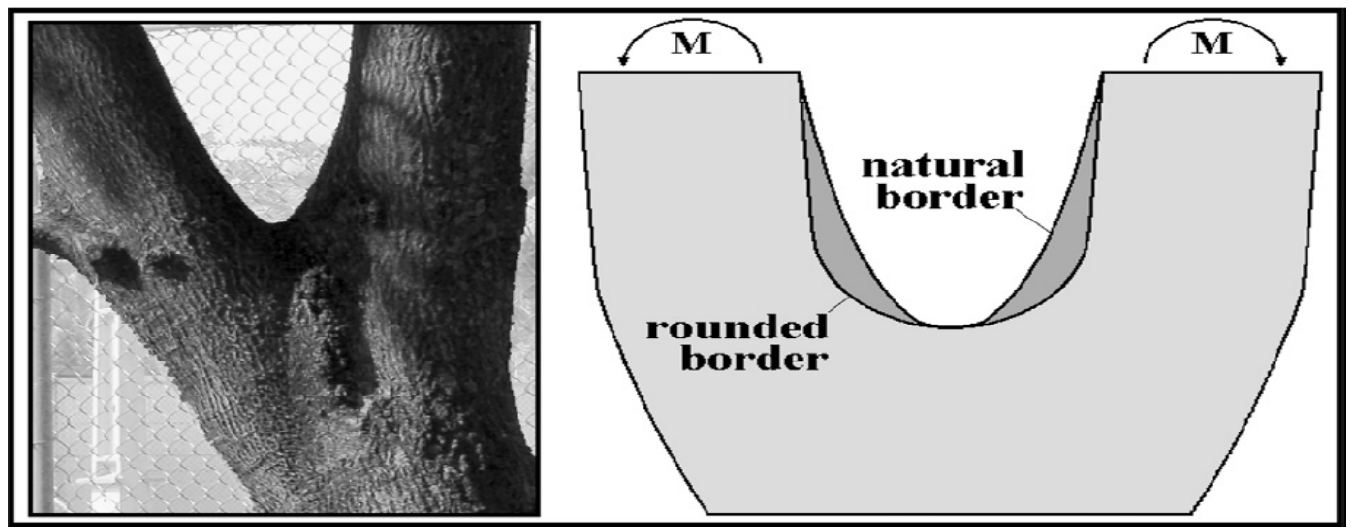

Fig.1. Natural notches usually do not have a constant radius tip to minimize stress concentration, [12], [13]

Mattheck projected an easy process for getting better notch shapes based on the apparent self-growth mechanism of tree branches. SCF can be reduce by shaping their contour to alternative bent force lines around their borders by stretched ones, the major plan behind the "method of tensile triangles" for getting better the notch geometry. So, according to Mattheck, sharp corner-like notches can be reinforced by a tensile triangle to decrease its local stresses, creating two fresh notches with less dangerous larger angles, and be further smooth starting with a 45 degree rectangular triangle and them consecutively adding obtuse isosceles triangles to strengthen the weaker notch side. The extra triangles, the lesser are the Kt of the better notch. [12], [13], [15]

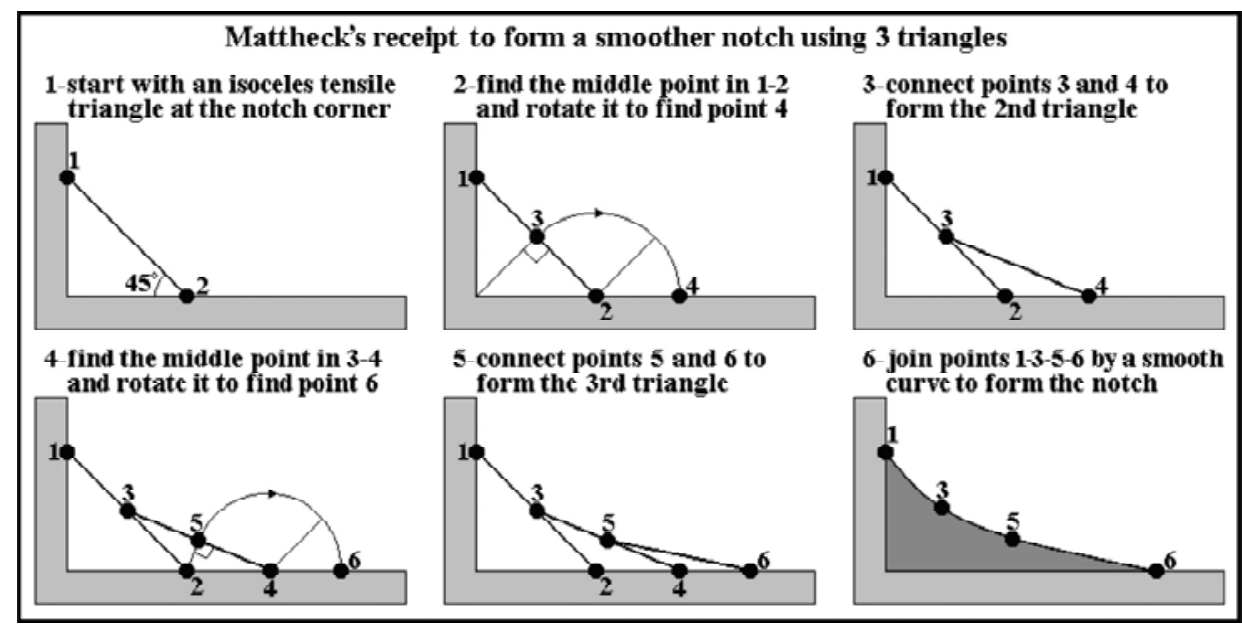

Fig. 2. Mattheck's tensile triangle method to improve notch profiles [12], [13]

\section{PROBLEM DESCRIPTION}

The Waveguide LR 260 Upper is used as transmission member in VFD motor. Transmission Member is fails due to combine effect of bending and torsion during working. During operation it was observed that the Waveguide LR 260 upper is bending and/or twisted after certain periods of working cycle. So the industry has to replace the Failure Waveguide LR 260 Upper which is not cost effective.

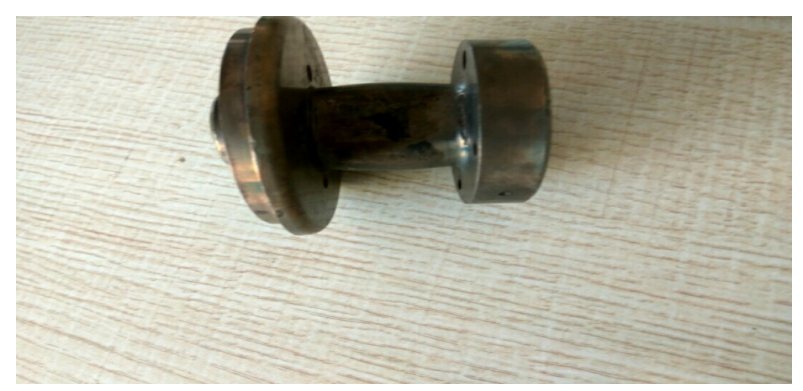

Fig -3.Waveguide LR Upper 260 rejected part sample 


\section{III.BASIC ARRANGEMENT OF DRIVE SYSTEM}

The shaft examined in this paper failed after 35 to 45 days of installation. The basic drive arrangement is shown in (Fig. 4), applied with $5600 \mathrm{~N}$ force in vertical direction. The drive arrangement consists of a $7.1 \mathrm{Kw}$ servo motor and belt drive for power transmission. The function of this arrangement is to rotate the Load drum. The load drum rotates at $900 \mathrm{rpm}$. The geometry of the shaft with its dimension is shown in Fig. 5. The material of the shaft under consideration is stainless steel 304. Since the shaft is working in a USA the operating temperature is at around Avg. $21.5^{\circ} \mathrm{C}$. It can be seen that the failure has taken place at the shoulder fillet that has been provided in the shaft were the stress concentration would be more due to abrupt change in cross section of the shaft.
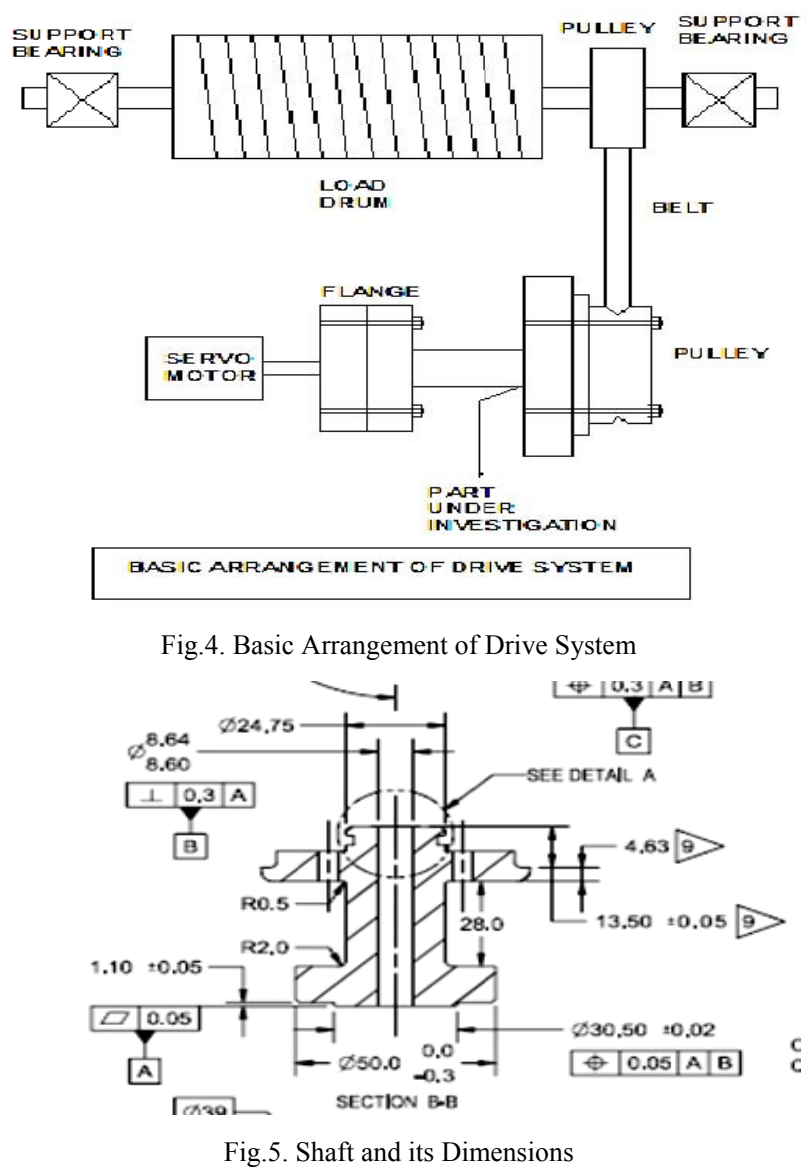

\section{IV.METHDOLOGY}

- Observing and comparing the Von-Misses stress, shear stress and Stress concentration of Constant Radius fillet with Variable Radius fillet.

- Comparing the Stress analysis results by using the Theoretical and FEA.

- Mattheck Method is used for converting Constant Radius into Variable Radius to reduce the effect of stress concentration.

- Master cam X4 is used to generate CNC Programmed for manufacturing point of view.

\section{DESIGN AND OPTIMIZATION}

Design of shaft is quite key aspect in any machines or mechanical system. Geometry of shaft plays a significant function and its mounting conditions are also considered while designing the shaft. The strength of shaft is a key aspect; it will decide that how much load a shaft can hold up. Based on loading stresses are calculate and then using those standard equation of stresses the design is completed. Another aspect to design the shaft is on rigidity basis. A shaft is a beam that deflects transversely and it is a torsion bar that deflects torsionally. Both mode of deflection are analyzed. The allowable angle of twist is to be calculated while designing the shaft on torsional rigidity bases. 


\section{A. Design of shaft}

From industrial data: $\mathrm{P}=7.1 \mathrm{~kW} \quad ; \mathrm{N}=900 \mathrm{RPM}$; Material and their properties: Material of shaft of gear motor is Stainless steel: Sut/Syc $=515 \mathrm{Mpa}$; Sys $=205 \mathrm{Mpa}$; (as considering Factor of Safety i.e. F.S =1), [2], [4], [6]

Therefore Tensile /Bending stresses in shaft, [2], [4], [6]

$\sigma b=\frac{s u t}{f . S}=515 \mathrm{mpa}$

And Shear stresses in shaft

$\tau=\frac{s y s}{f . s}=205 \mathrm{mpa}$

Servo motor Power, [2], [4], [6]:

$\mathrm{P}=\frac{2 \pi N T}{60}$

$7.1=(2 \pi \times 900 \times \mathrm{T}) / 60$

$71.6 \mathrm{~N}-\mathrm{M}$

$\mathrm{T}=71600 \mathrm{~N}-\mathrm{mm}$

Torque on pulley: Ratio for belt tension for pulley is 2.5

$\frac{F B 1}{F B 2}=2.5$

$\mathrm{FB} 1+\mathrm{FB} 2=5600 \mathrm{~N}$

$\mathrm{T}=(\mathrm{FB} 1-\mathrm{FB} 2) \times(\mathrm{d} / 2)$

$71600=(2.5 \mathrm{FB} 2-\mathrm{FB} 2) \times(59.7 / 2)$

$71600=1.5 \times \mathrm{FB} 2 \times 29.85$

$\mathrm{FB} 2=1599.10 \mathrm{~N}$

$\mathrm{FB} 1=3997.77 \mathrm{~N}$

Maximum bending moment of shaft:

$\mathrm{M}=\mathrm{F} \times \mathrm{L}$

$=5600 \times 41.5$

$\mathrm{M}=232400 \mathrm{~N}-\mathrm{mm}$

Failure of shaft under twisting moment, [2], [4], [6]:

AS shaft is a step shaft having maximum diameter $60 \mathrm{~mm}$ and minimum diameter of $24.75 \mathrm{~mm}$, so we consider minimum diameter for failure i.e. $24.75 \mathrm{~mm}$

Equivalent torque;

$T e=\sqrt{\left(M^{2}+\right.} T^{2}$

$T e=\sqrt{232400^{2}+71600^{2}}$

$\mathrm{Te}=243179.60 \mathrm{~N}-\mathrm{mm}$

$\tau=\frac{16 \times T e}{\pi \times\left(d o^{3}\right) \times\left[1-k^{4}\right]}$

Where; $\mathrm{di}=$ inner diameter $\&$ do $=$ outer diameter

$\mathrm{K}=\frac{d i}{d o}$

$\tau=\frac{16 \times 243179.60}{\pi \times\left(24.75^{3}\right) \times\left[1-0.35^{4}\right]}$

Shear stress....... $\tau=82.93 \mathrm{mpa}$

Failure of shaft under Bending, [2], [4], [6]:

$\sigma b=\frac{32 \times M}{\pi \times\left(d o^{3}\right) \times\left[1-k^{4}\right]}$

$\sigma b=\frac{32 \times 232400}{\pi \times\left(24.75^{3}\right) \times\left[1-0.35^{4}\right]}$

Bending stress...... $. \sigma b=158.51 \mathrm{mpa}$

Now, using Maximum Principle /normal stress Theory, [2], [4], [6]: 
$\operatorname{Max} . \sigma b=\frac{\sigma b}{2}+\frac{1}{2} \sqrt{\sigma b+4 \tau^{2}}$

$\operatorname{Max} . \sigma b=\frac{158.51}{2}+\frac{1}{2} \sqrt{158.51+4\left(82.93^{2}\right)}$

Max. $\sigma=193.96 \mathrm{mpa}$

Minimum principle stresses are, [2, 4, and 6]:

$\operatorname{Max} . \sigma b=\frac{\sigma b}{2}-\frac{1}{2} \sqrt{\sigma b+4 \tau^{2}}$

$\operatorname{Max} . \sigma b=\frac{158.51}{2}-\frac{1}{2} \sqrt{158.51+4\left(82.93^{2}\right)}$

Min. $\sigma=-35.46 m p a$

Thus the corresponding maximum shear stress is, [2], [4], [6]:

$\operatorname{Max} . \tau=\frac{1}{2} \sqrt{\sigma b+4 \tau^{2}}$

$\operatorname{Max} . \tau=\frac{1}{2} \sqrt{158.51+4(982.93)^{2}}$

$\operatorname{Max} . \tau=114.71 \mathrm{mpa}$

Von- Misses Stresses are, [2], [4], [6]:

$\sigma$ mises $=\sqrt{\sigma 1^{2}-\sigma 1 \times \sigma 2+\sigma 2^{2}}$

$\sigma$ mises $=213.9 \mathrm{mpa}$

B. Design for stress concentration

Diameter of larger shaft section $=\mathrm{D}=40 \mathrm{~mm}$

Diameter of smaller shaft section $=\mathrm{d}=24.75$

Radius $=r=2 \mathrm{~mm}$

Bending moment $=\mathrm{M}=232.4 \mathrm{~N} . \mathrm{m}$

Torque $=\mathrm{T}=71.6 \mathrm{~N} . \mathrm{m}$

Height $=\mathrm{h}=12.62 \mathrm{~mm}$

Stress concentration factor in bending, [3], [5], [7]:

For ration, $2.0<\mathrm{h} / \mathrm{r}<20.0$

$\mathrm{C}_{1}=1.232+0.832 \sqrt{\frac{h}{r}}-0.008 \frac{h}{r}$

$\mathrm{C}_{2}=-3.813+0.968 \sqrt{\frac{h}{r}}-0.260 \frac{h}{r}$

$\mathrm{C}_{3}=7.423-4.868 \sqrt{\frac{h}{r}}+0.869 \frac{h}{r}$

$\mathrm{C}_{4}=-3.839+3.707 \sqrt{\frac{h}{r}}-0.600 \frac{h}{r}$

$\mathrm{Kt}=\mathrm{C}_{1}+\mathrm{C}_{2}(2 \mathrm{~h} / \mathrm{D})+\mathrm{C}_{3}(2 \mathrm{~h} / \mathrm{D})^{2}+\mathrm{C}_{4}(2 \mathrm{~h} / \mathrm{D})^{3}$

$\sigma_{\text {nom }}=\frac{32 M}{\pi d^{3}}$

$\sigma_{\text {max }}=K t \times \sigma$ nom

Stress concentration factor $=\mathrm{kt}=1.89$

Nominal tension stress at shaft $=\sigma_{\text {nom }}=156.14 \mathrm{mpa}$

Maximum tension stress due to bending $=\sigma_{\max }=294.57 \mathrm{mpa}$

Stress concentration factor in torsion, [3], [5],[7]:

For ratio, $0.25<\mathrm{h} / \mathrm{r}<4.0$

$\mathrm{C}_{1}=0.905+0.783 \sqrt{\frac{h}{r}}-0.075 \frac{h}{r}$

$\mathrm{C}_{2}=-0.437-1.969 \sqrt{\frac{h}{r}}+0.553 \frac{h}{r}$ 


$$
\begin{aligned}
& \mathrm{C}_{3}=1.557+1.073 \sqrt{\frac{h}{r}}+0.086 \frac{h}{r} \\
& \mathrm{C}_{4}=-1.061+0.171 \sqrt{\frac{h}{r}}+0.086 \frac{h}{r} \\
& \mathrm{Kt}=\mathrm{C}_{1}+\mathrm{C}_{2}(2 \mathrm{~h} / \mathrm{D})+\mathrm{C}_{3}(2 \mathrm{~h} / \mathrm{D})^{2}+\mathrm{C}_{4}(2 \mathrm{~h} / \mathrm{D})^{3} \\
& \tau_{\text {nom }}=\frac{16 \times T}{\pi d^{3}} \\
& \tau_{\text {max }}=K t \times \tau \text { nom }
\end{aligned}
$$

Stress concentration factor $=\mathrm{kt}=1.51$

Nominal shear stress at shaft ${ }^{*} \tau_{\text {nom }}=24.05 \mathrm{mpa}$

Maximum shear stress due to torsion $=\tau_{\max }=36.27 \mathrm{mpa}$

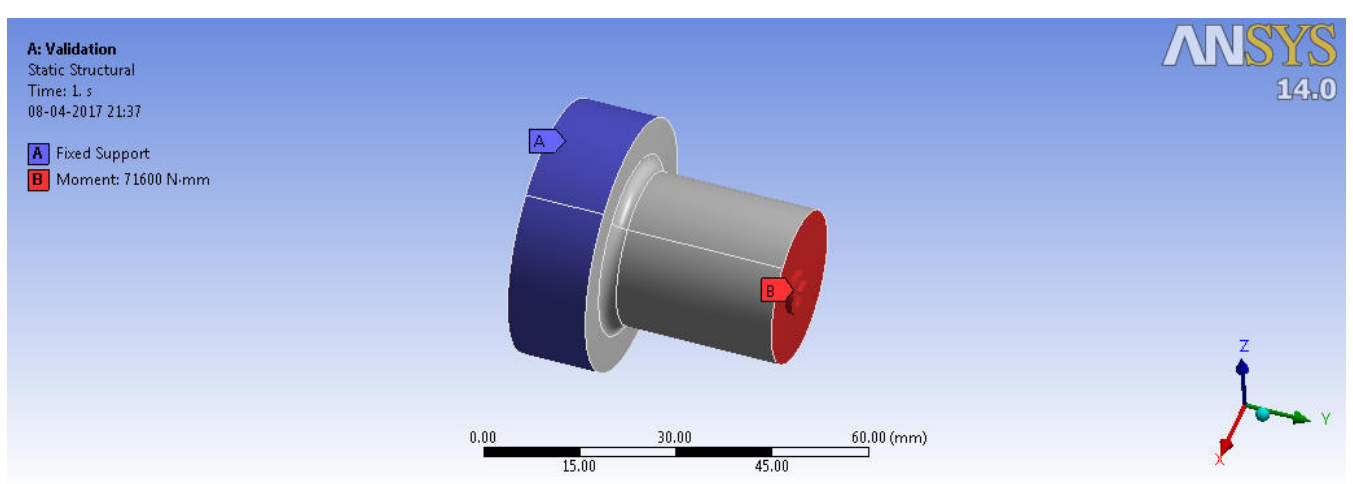

Fig.6. Boundary condition- Software Validation

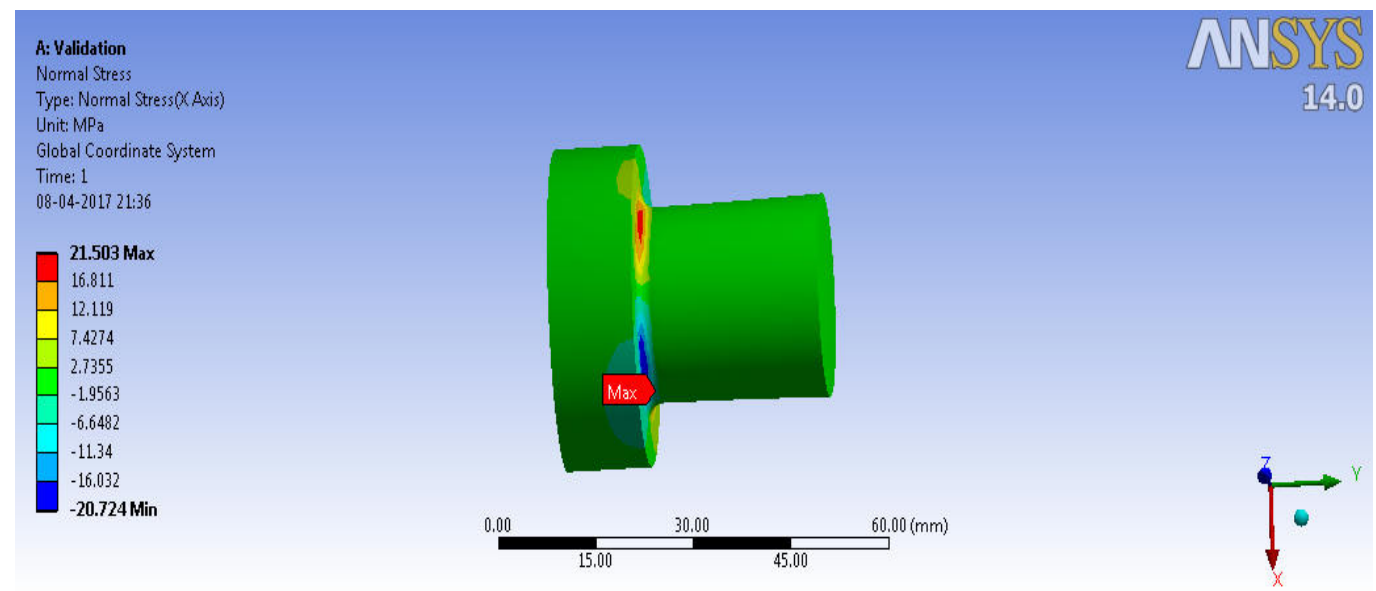

Fig.7.Normal Stresses- Software Validation

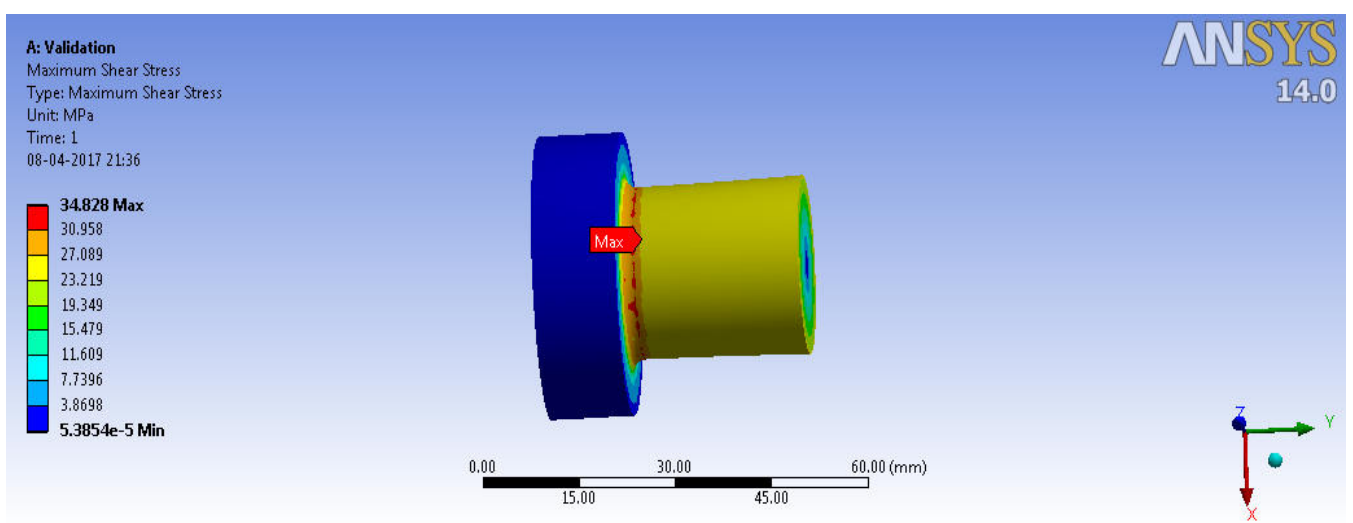

Fig.8.Maximum shear stress- Software Validation 


\section{VI.FEA ANALYSIS}

A. Constant radius geometry

First, we prepare a model of shaft in Catia v5 software and save as .IGES file format for Analysis of shaft in ANSYS WORKBENCH 14. Import .IGES model in ANSYS Workbench simulation module. Material type:stainless steel 304; Poisson ratio: - 0.3; Modulus of Elasticity: - 193 GPA; Modulus of rigidity G=74.23 Gpa =E/ $(2(1+v))$

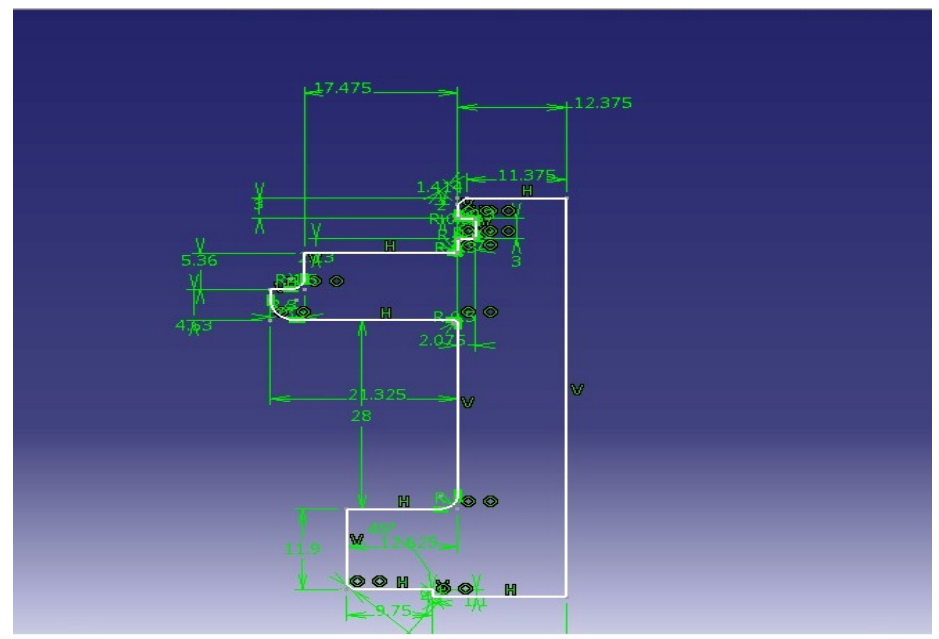

Fig.9.Catia v 5 geometry of waveguide LR 260

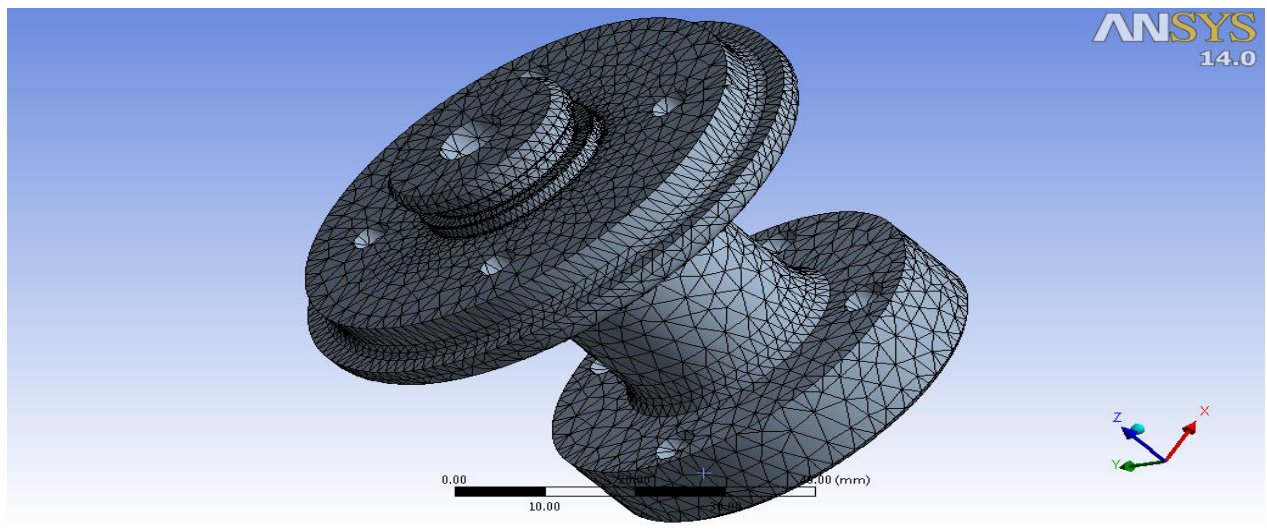

Fig.10.Meshing

Define boundary condition for analysis:

Fixed support applies on one side of shaft, Force $(5600 \mathrm{~N})$ Tangential is apply on one side of shaft \& Moment (71600 N.mm) is apply on one side of shaft.

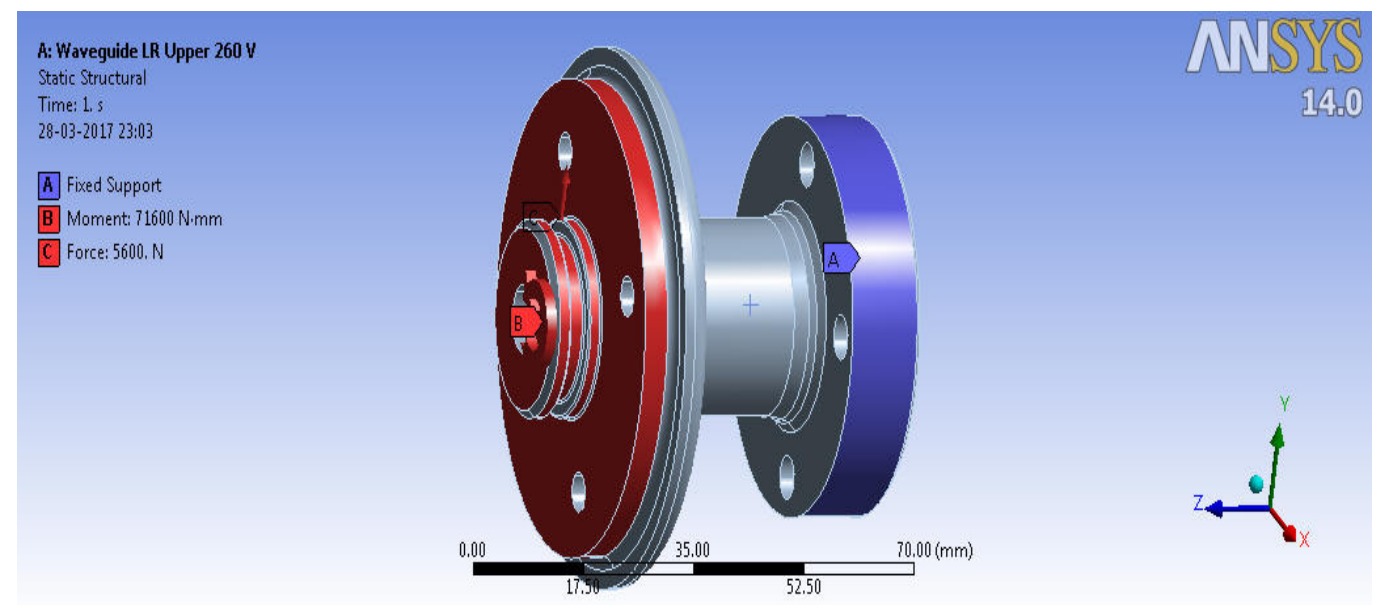

Fig.11.Define boundary condition for analysis 
ISSN (Print) : :2319-8613

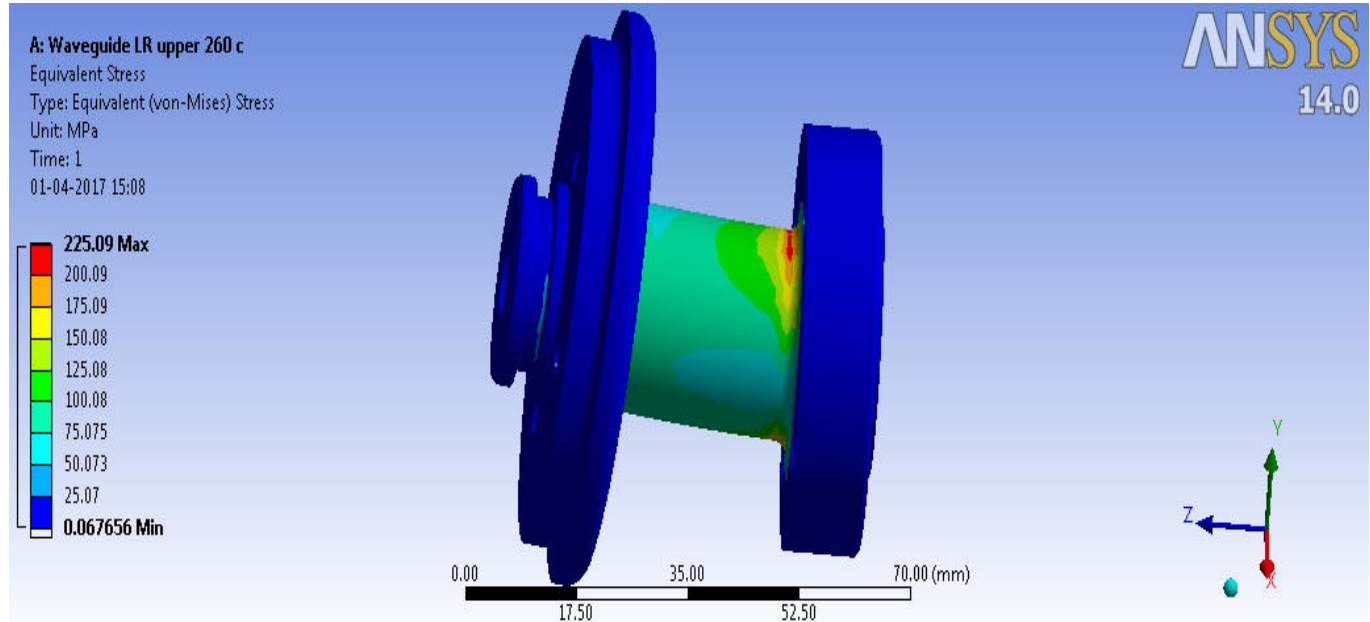

Fig.12. Von-Misses Stress analysis

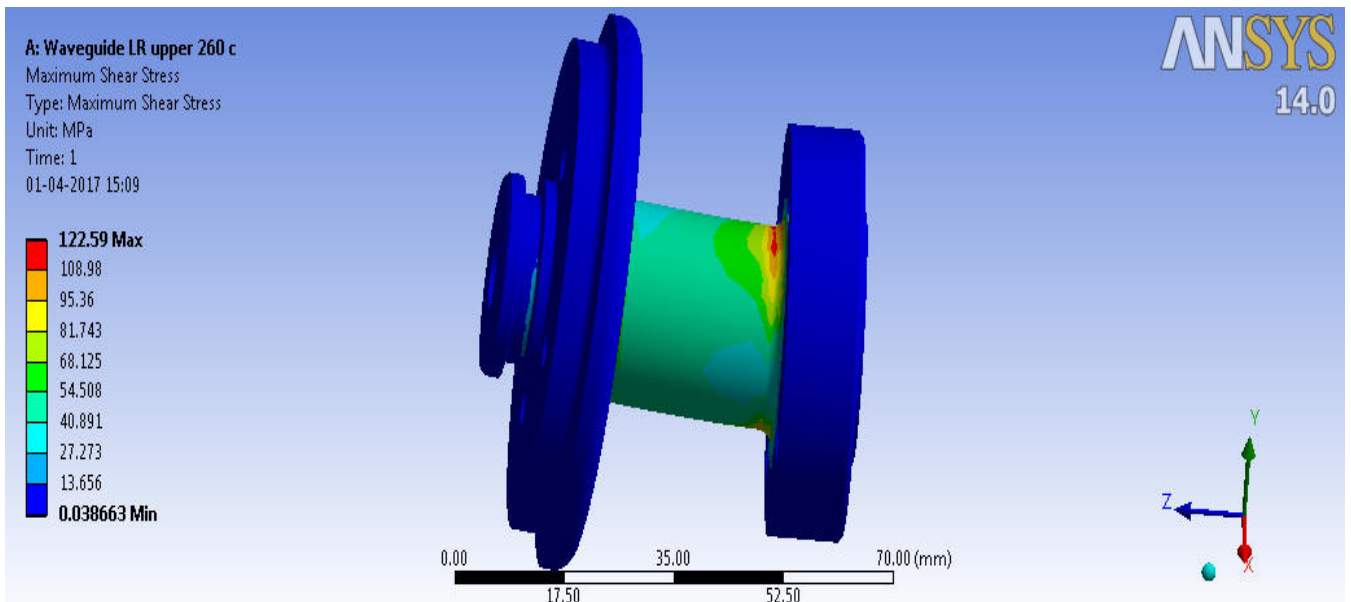

Fig.13. Shear stress analysis

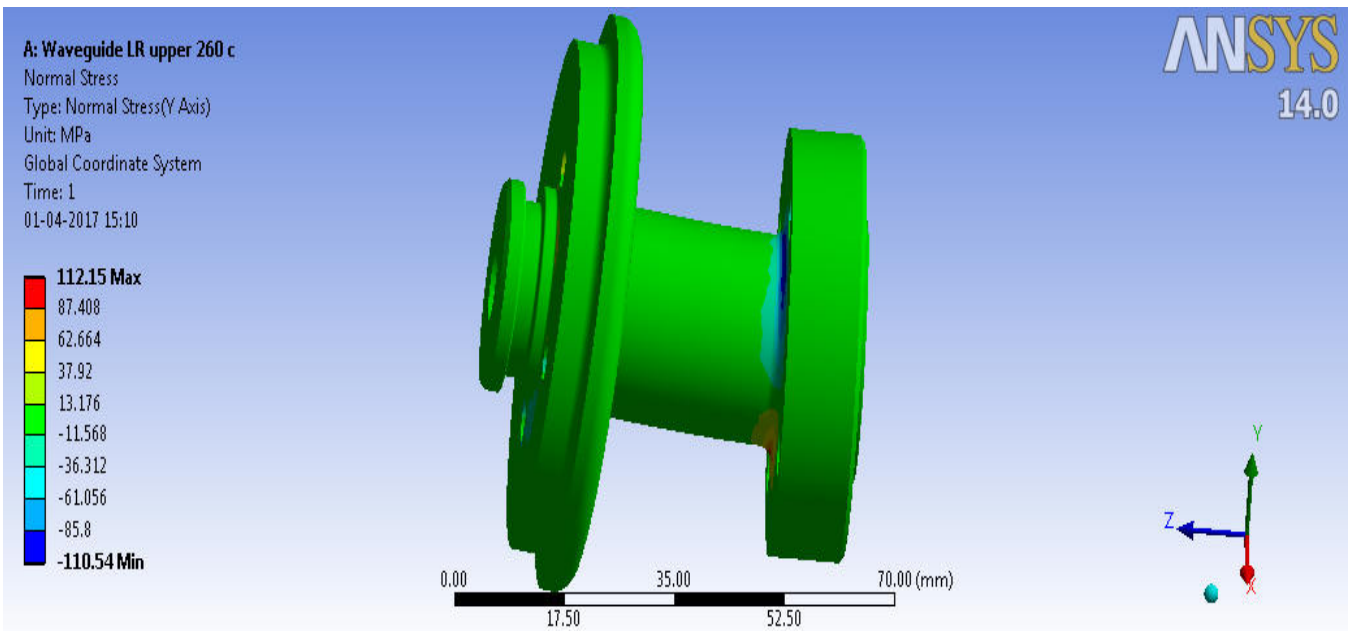

Fig.14.Nominal Stresses 
TABLE I. Comparison between Theoretical and FEA Analysis stress (Mpa) values

\begin{tabular}{|l|l|l|l|l|}
\hline Sr. No. & Types of stress & Theoretical stress & FEA Analysis & \% error \\
\hline 1 & Von-Misses stresses (mpa) & 213.9 & 225.09 & $4.97 \%$ \\
\hline 2 & Shear stresses (mpa) & 114.71 & 122.59 & $6.42 \%$ \\
\hline 3 & Kt $\sigma$ & 1.34 & 1.42 & $5.63 \%$ \\
\hline 4 & Kt $\tau$ & 1.38 & 1.47 & $6.12 \%$ \\
\hline
\end{tabular}

B. Modified variable radius geometry by Mattheck method

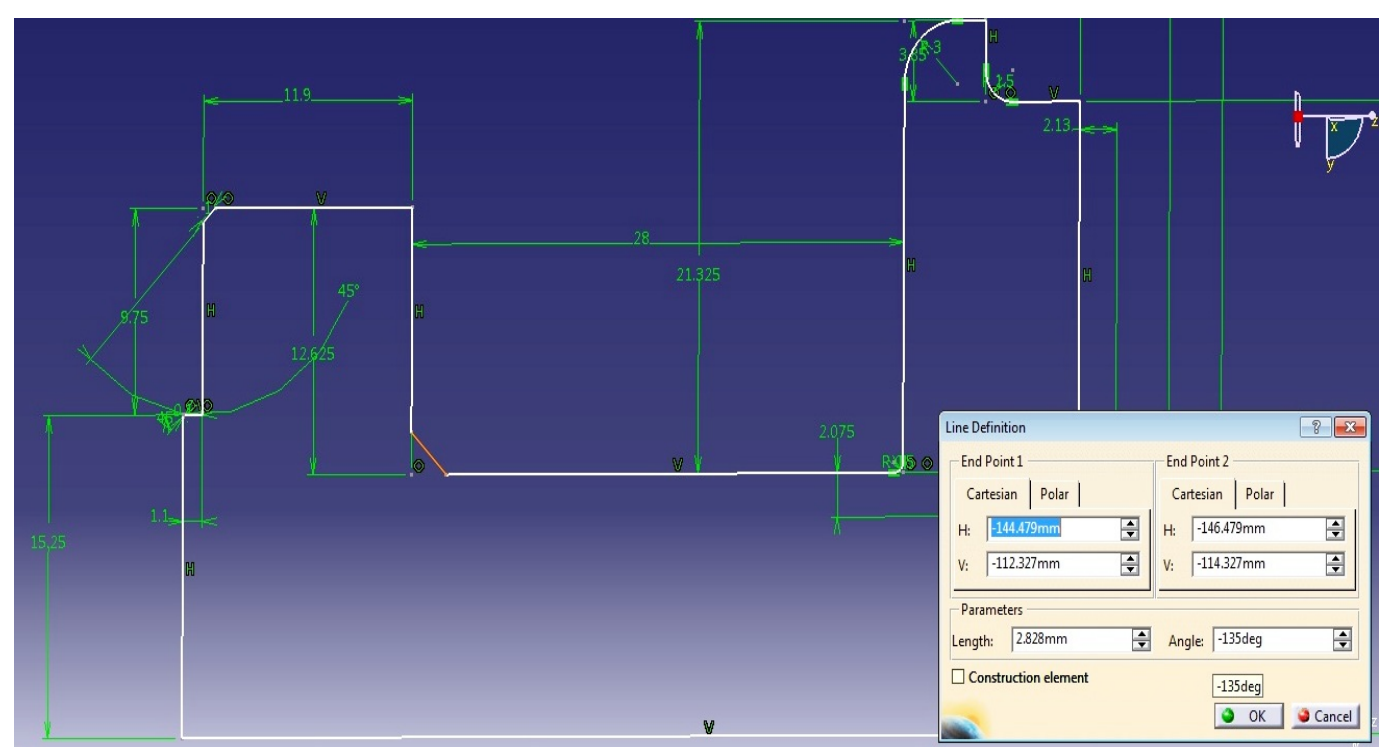

Fig.15.Variable Radius geometry in catia v5-a

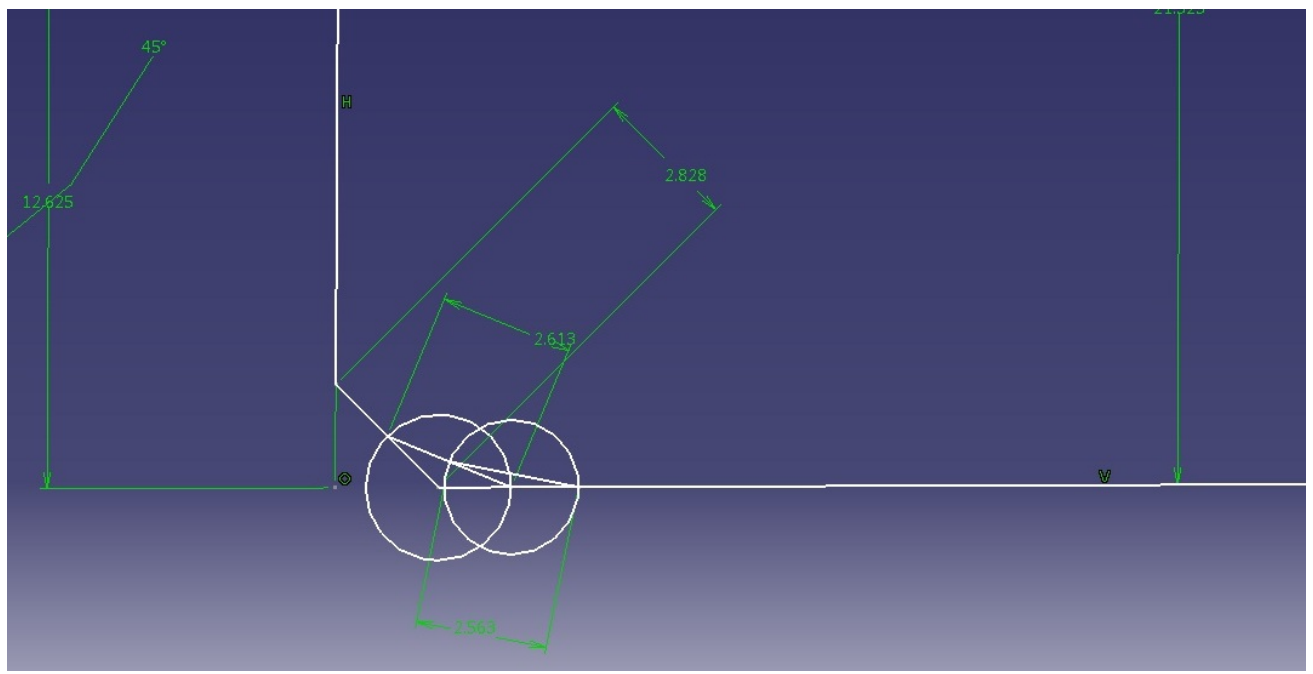

Fig.16. Variable Radius geometry in catia v5-b 


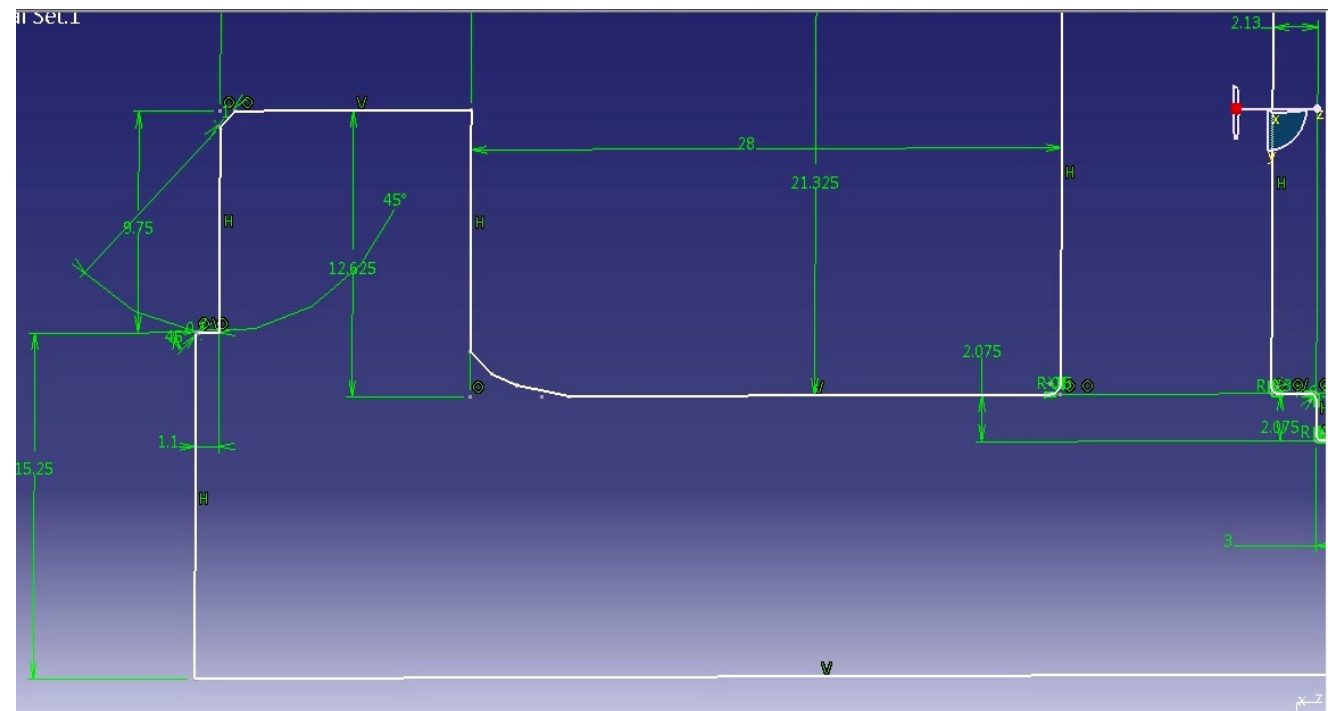

Fig.17. Variable Radius geometry in catia v5-c

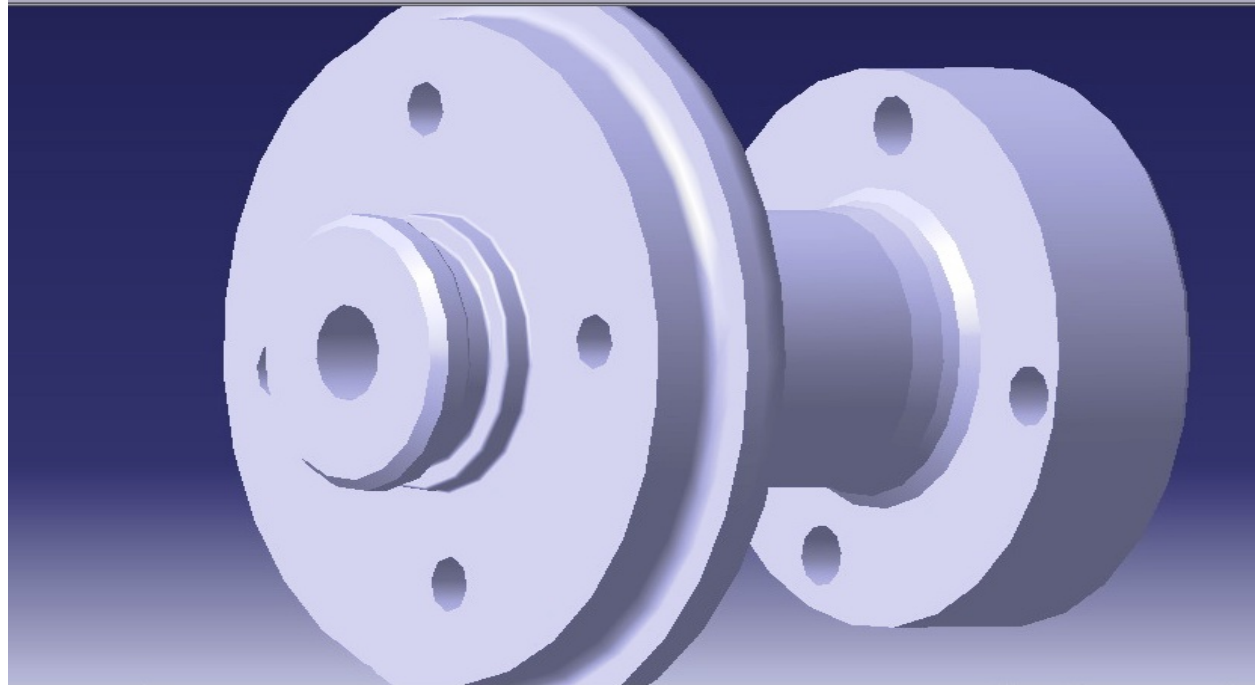

Fig.18. Variable Radius geometry in catia v5-d

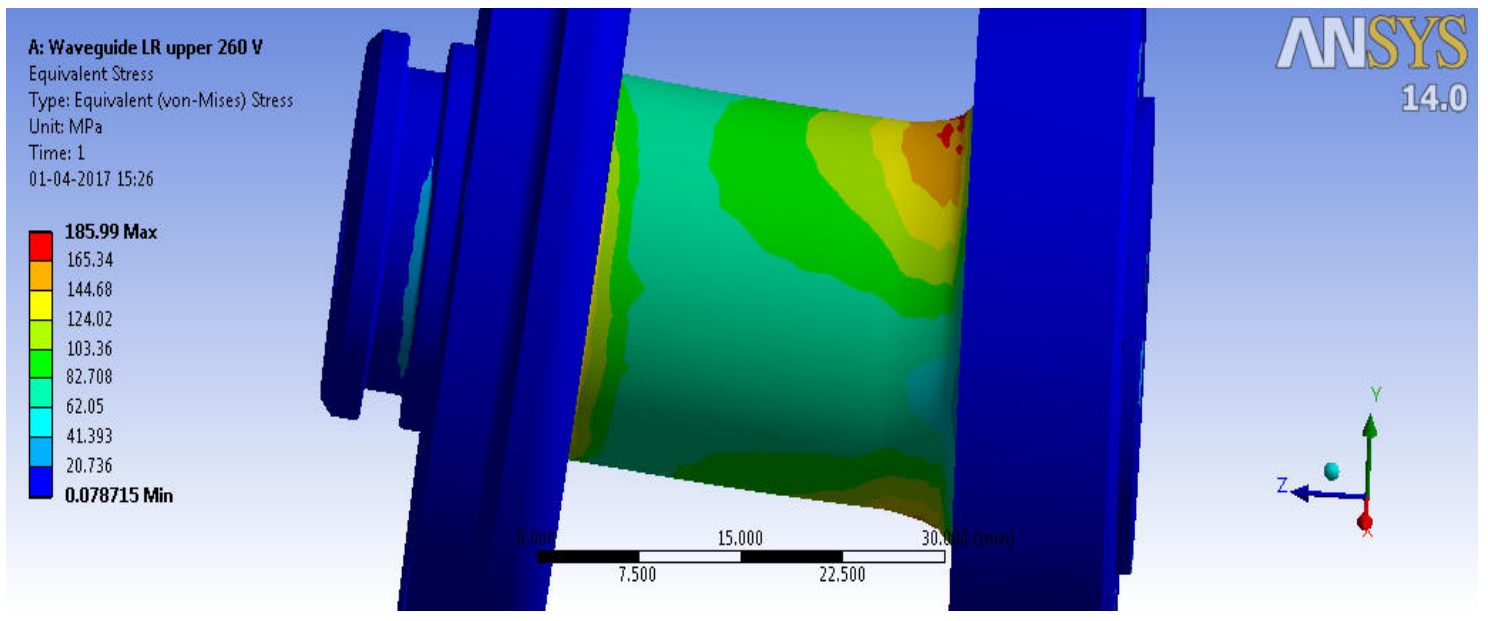

Fig.19. Von-Misses Stress analysis- Variable Radius geometry 


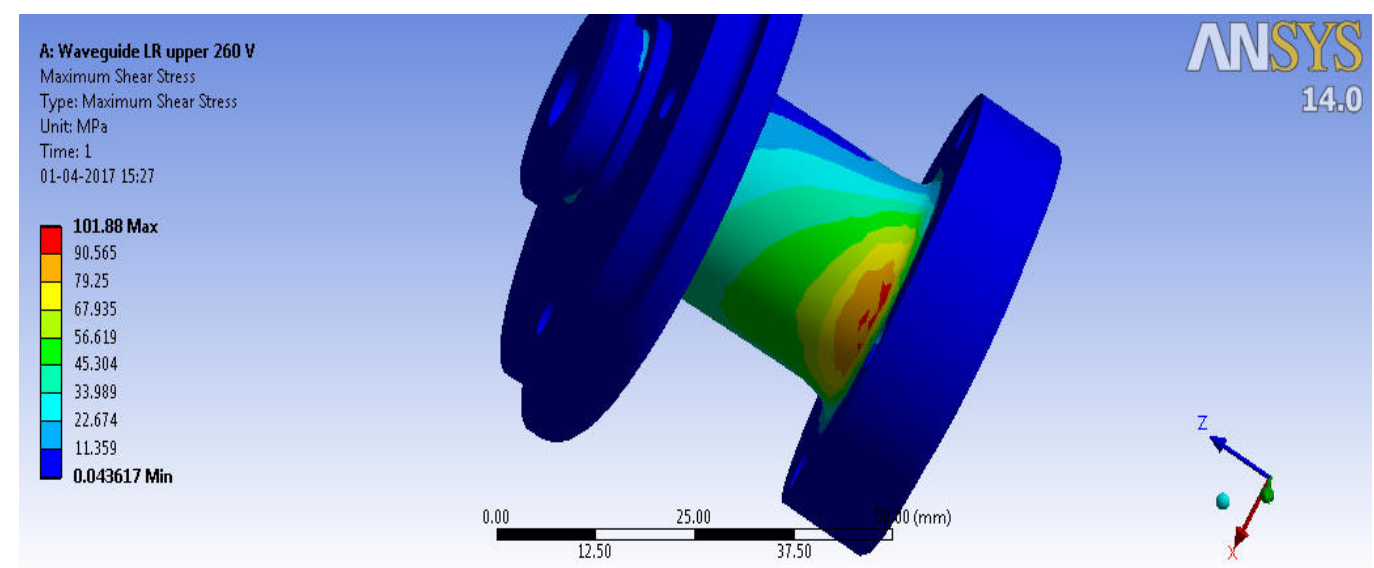

Fig.20.Maximum shear stress analysis- Variable Radius geometry

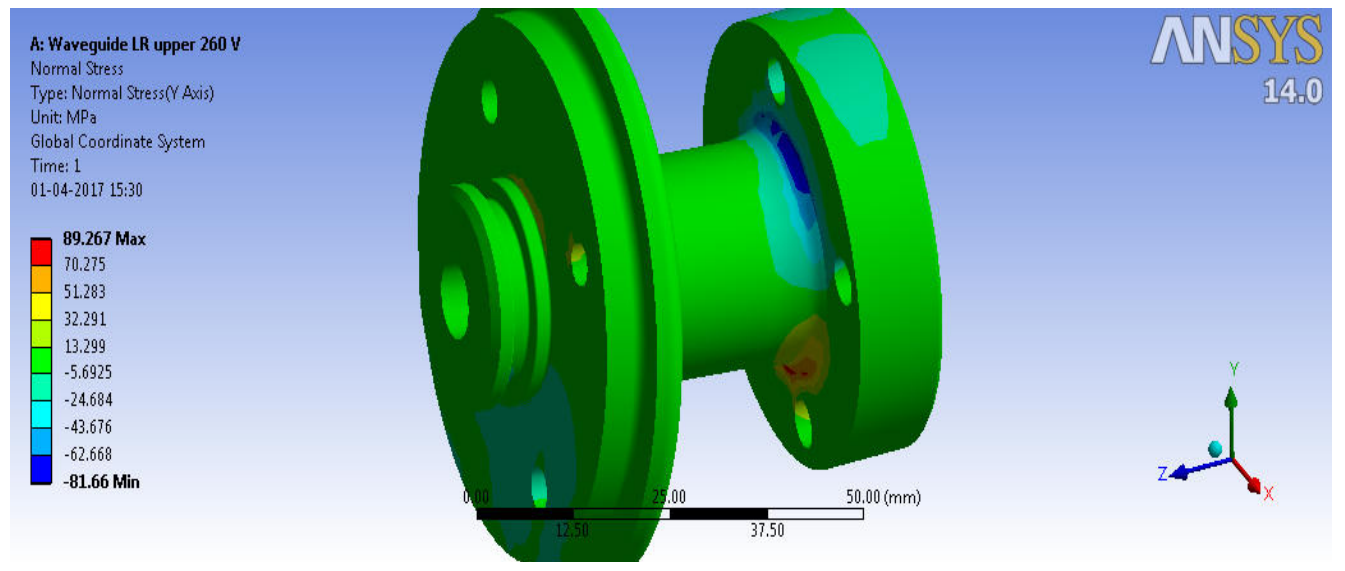

Fig.21.Nominal Stresses- Variable Radius geometry

TABLE II. Comparison between Constant Radius and Variable Radius fillet by FEA Analysis

\begin{tabular}{|l|l|l|l|l|}
\hline Sr. No. & Types of stress & $\begin{array}{l}\text { Constant } \\
\text { Radius Fillet }\end{array}$ & $\begin{array}{l}\text { Variable } \\
\text { Radius fillet }\end{array}$ & $\begin{array}{l}\text { \% stress } \\
\text { reduced }\end{array}$ \\
\hline 1 & Von-Misses stresses (mpa) & 225.09 & 185.99 & $17.37 \%$ \\
\hline 2 & Maximum Shear stresses (mpa) & 122.59 & 101.88 & $16.89 \%$ \\
\hline 3 & Kt $\sigma$ & 1.42 & 1.17 & $17.60 \%$ \\
\hline 4 & Kt $\tau$ & 1.47 & 1.22 & $17.00 \%$ \\
\hline
\end{tabular}

VII. MANUFACTURING

Master cam $\mathrm{x} 4$ is computer-based computer-aided design/computer-aided manufacturing (CAD/CAM) software. Master cam X4 CNC Software's main product, started as a 2D CAM system with CAD tools that use by machinists design virtual components on a computer screen as well as guided computer numerical controlled (CNC) machine tools in the manufacture of components.

Master cam program for variable radius:

- Geometry Creation

- Setting the Environment

- Setting the Construction Planes

- Create the Geometry

- $\quad$ Create the Fillets (Radius)

- $\quad$ Save the Drawing

Tool path Creation

- Define the Stock and Chuck Parameters

- Face front of the part

- Rough the outside diameter 
- Finish the outside diameter

- Cut of the part

- Back plot the tool path

- Verify the tool path

- Save and updated master cam file

- $\quad$ Post and create the CNC code file

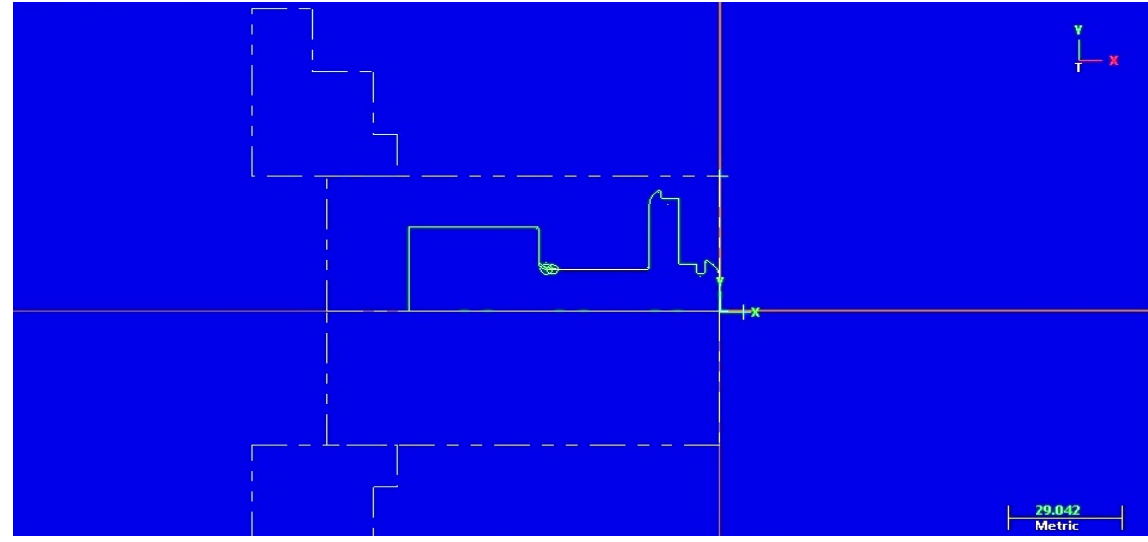

Fig.22. Geometry Creation

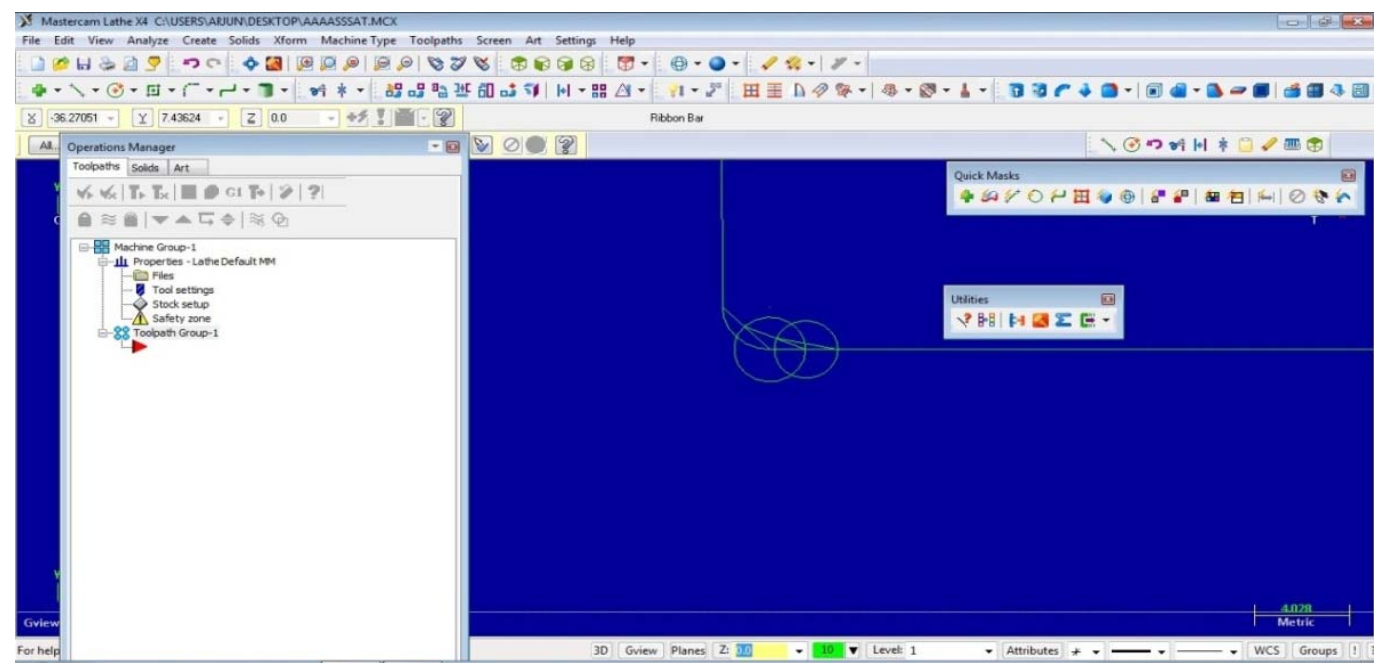

Fig.23. Variable Radius geometry in master cam $\mathrm{x} 4$

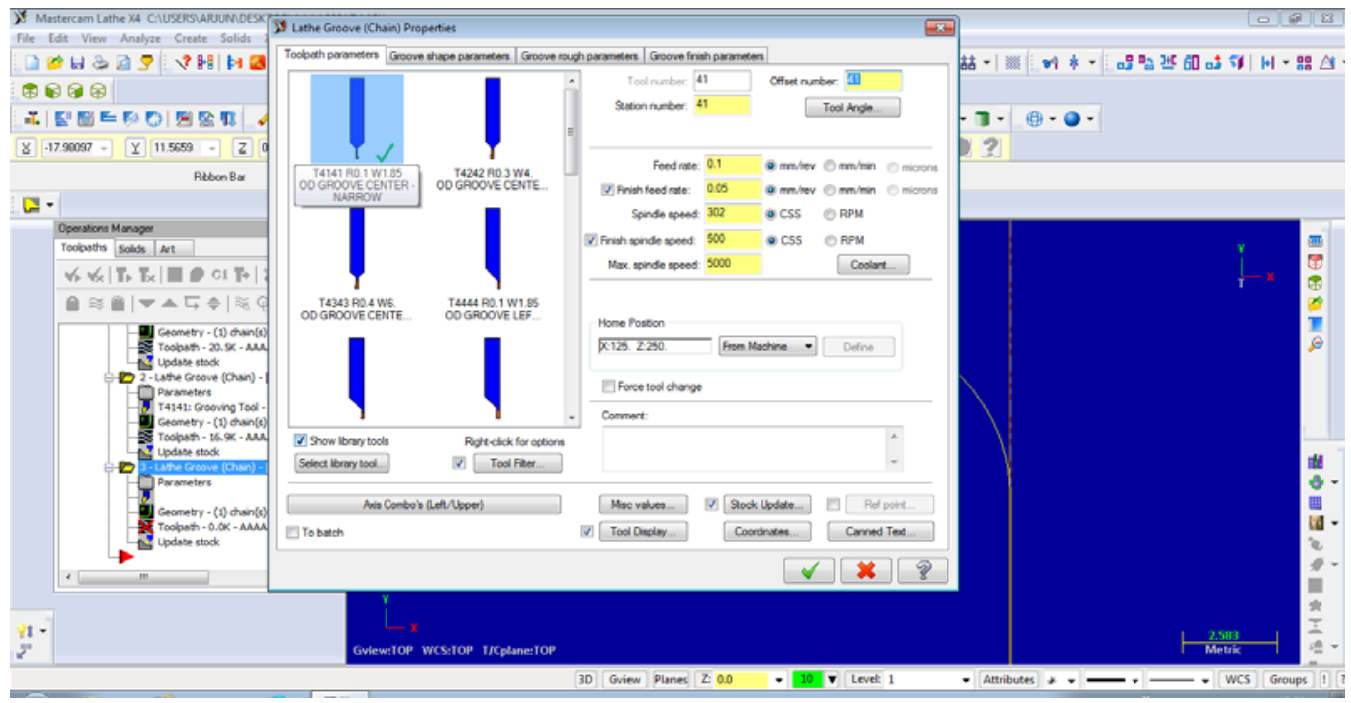

Fig.24. Tool\& its path Creation 


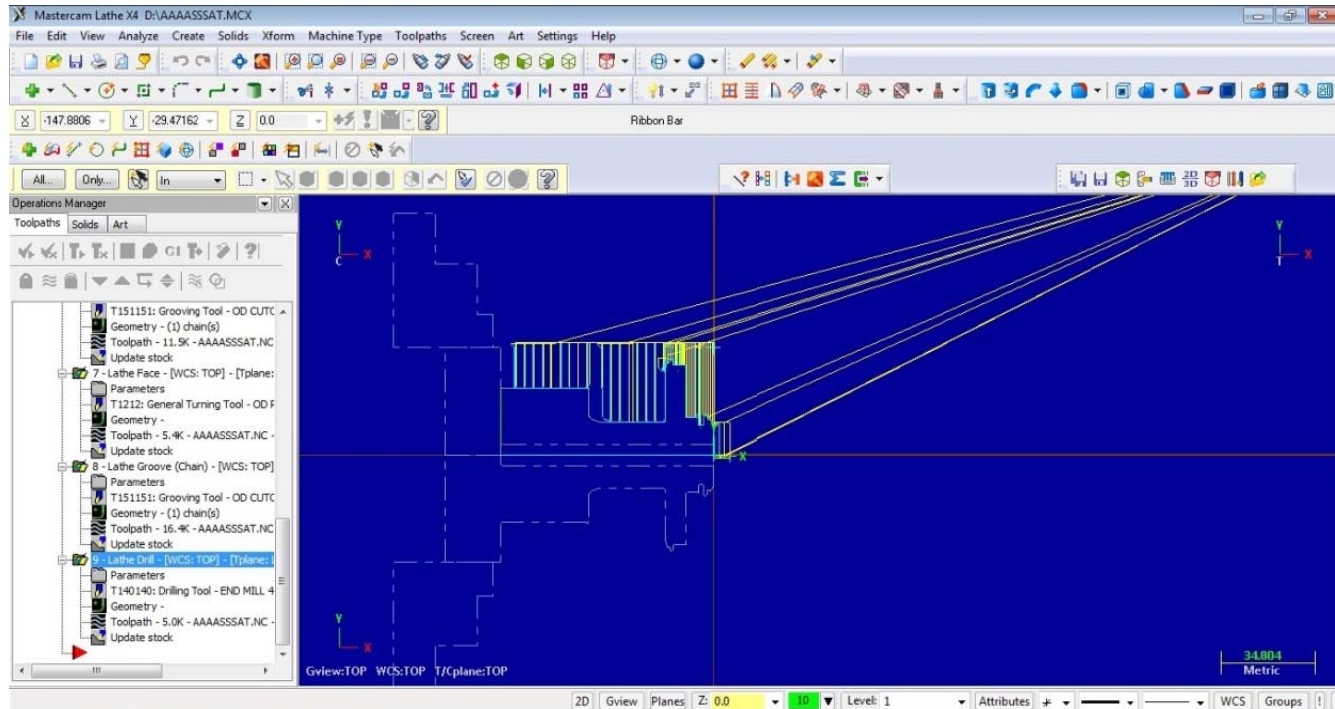

Fig.25. Back plot the tool path

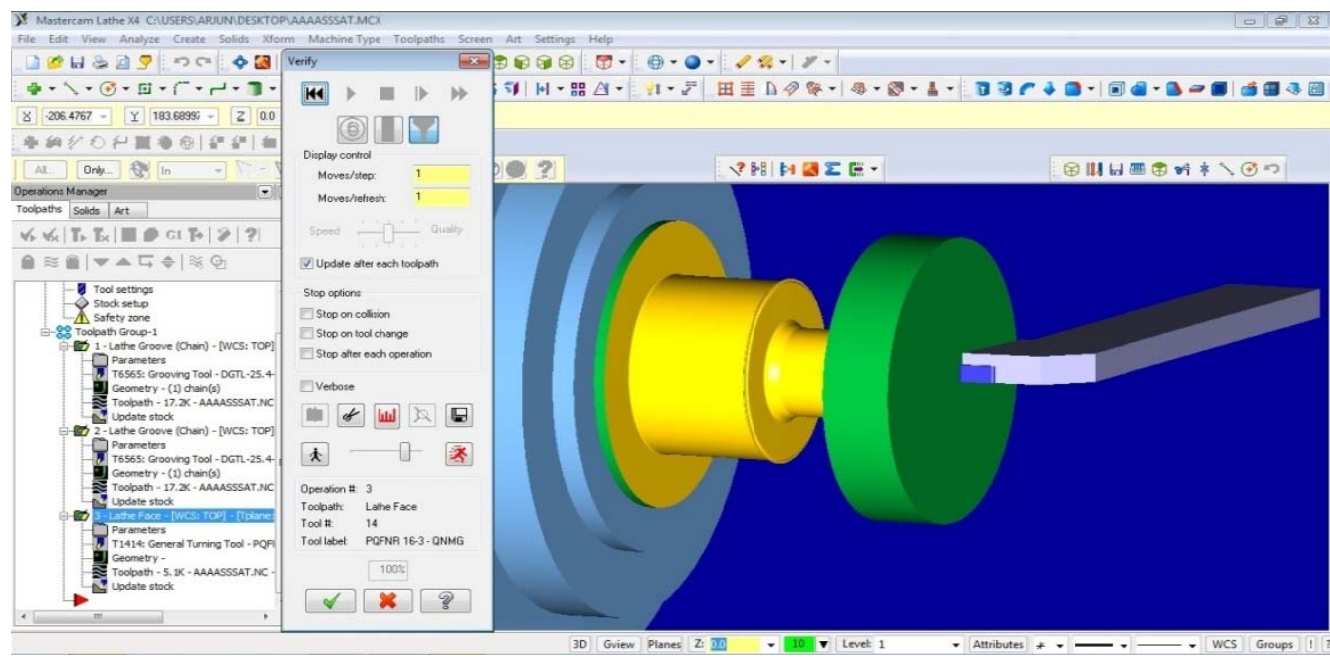

Fig.26. Verify the tool path

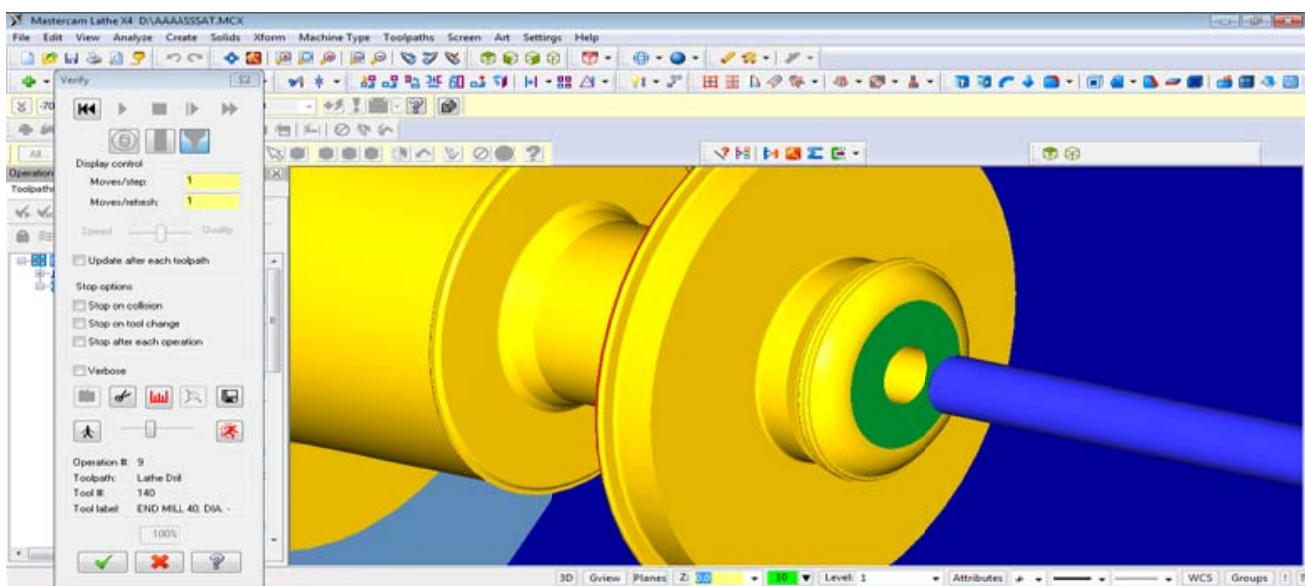

Fig.27 Post and create the $\mathrm{CNC}$ code file 


\section{RESULT AND DISCUSSION}

The effects of Von- misses stress, Maximum shear stress and stress concentration factor $(\mathrm{Kt})$ can be reduced to a great extent .Von-misses stress reduces up to $17.37 \%$, Maximum shear stress up to $16.89 \%$ and stress concentration factor Bending and Torsion up to $17.60 \& 17.00 \%$ respectively by Converting fillet radius geometry of the components, i.e. variable-radius notch as a replacement for constant-radius notch.

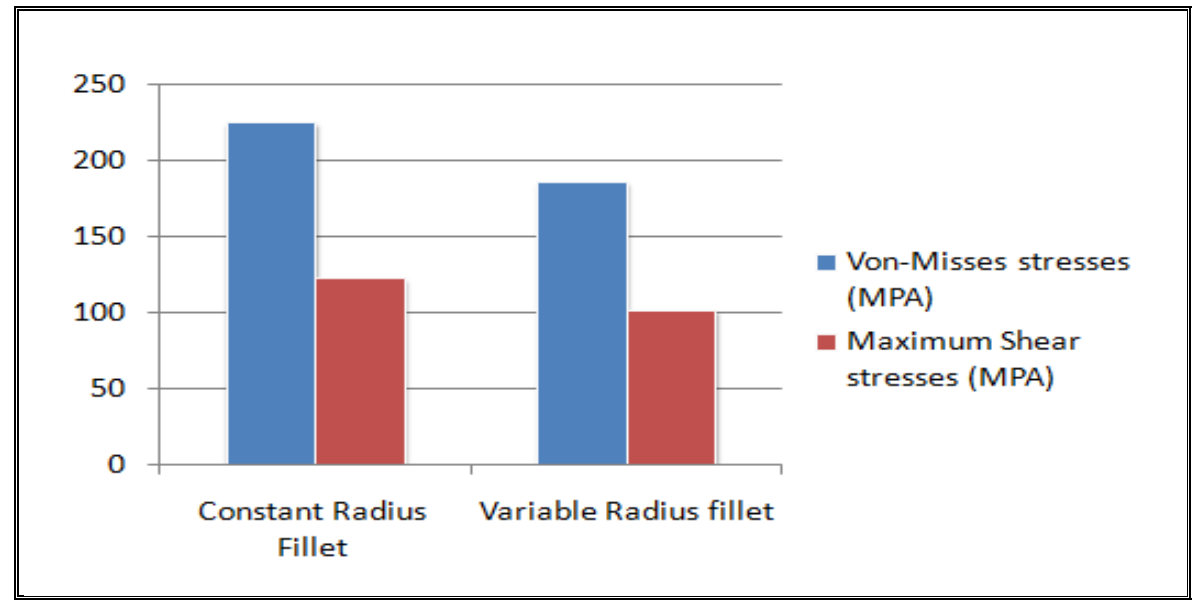

Fig.28.Von-mises stress and Max.shear stress for constant radius \&Variable Radius

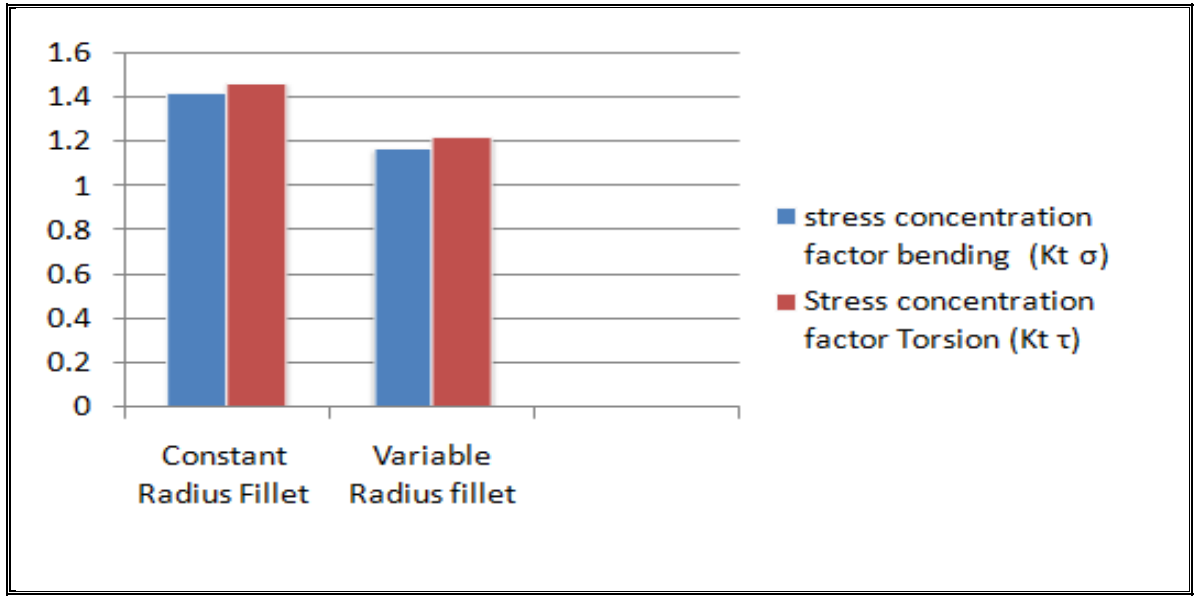

Fig.29.Stress concentration factor for constant and variable radius

\section{IX.CONCLUSION}

The effects of Von- misses stress, Maximum shear stress and stress concentration factor $(\mathrm{Kt})$ can be reduced to a great extent .Von-misses stress reduces up to $17.37 \%$, Maximum shear stress up to $16.89 \%$ and stress concentration factor Bending and Torsion up to $17.60 \& 17.00 \%$ respectively by Converting fillet radius geometry of the components, i.e. variable-radius notch as a replacement for constant-radius notch. Stresses are calculated at critical section and there is no need to compute the stresses at every position. FEA analysis shows that maximum stress concentration at radius fillet and crack / or bending initiation also occurs at fillet radius. The Mattheck Method is capable of creating variable-radius notches with reduced to a great extent maximum stresses, using a very simple approach based on the apparent self-growth mechanism of tree branches. This approach could be very helpful in industrial areas by using advance CNC Programming software like Master cam X4 from manufacturing point of view.

\section{ACKNOWLEDGMENT}

The authors would like to thank Prof. G P Deshmukh, Professor, D Y Patil Institute of engineering and Technology, Ambi, Pune, and Er. Vinit Raut, Design Manager, Vijay Transtech, Mumbai for the encouragement during this study. 


\section{NOMENCLATURE}

$\begin{array}{ll}\text { Kt } & \text { Stress concentration factor } \\ \mathrm{p} & \text { Power }(\mathrm{Kw}) \\ \mathrm{N} & \text { Rotational Speed }(\mathrm{rpm}) \\ \mathrm{F} . \mathrm{S} & \text { Factor of safety } \\ \mathrm{F} & \text { Force }(\mathrm{N}) \\ \mathrm{T} & \text { Torque }(\mathrm{N}-\mathrm{mm}) \\ \mathrm{M} & \text { Bending Moment }(\mathrm{N}-\mathrm{mm}) \\ & \\ \text { Te } & \text { Equivalent torque }(\mathrm{N}-\mathrm{mm}) \\ \mathrm{di} & \text { Inner diameter } \\ \text { do } & \text { outer diameter } \\ \mathrm{K} & \text { Ration of diameters } \\ \mathrm{h} & \text { Height }(\mathrm{mm}) \\ \mathrm{r} & \text { Radius }(\mathrm{mm}) \\ \mathrm{D} & \text { Diameter of larger shaft section(mm) } \\ \mathrm{d} & \text { Diameter of smaller shaft section(mm) }\end{array}$

Greek
Symbols
$\sigma b$
$\tau$
$\sigma$ max
$\sigma_{\text {mises }}$
$\tau_{\text {Max }}$
Kt $\sigma$
Kt $\tau$
$\sigma$ nom
Sut
syt

Subscripts

S.S Stainless Steel

\section{REFERENCES}

[1] F S. Timoshenko, J. Goodier, Theory of Elasticity, McGraw-Hill, 1969.

[2] F.O. Sonmez, Optimal shape design of shoulder fillets for flat and round bars under various loadings, Proc. J. Mech. Eng. Sci. 223 (C8) (2009) 1741-1754.

[3] W. Pilkey, D. Pilkey, R. Peterson, Peterson's Stress Concentration Factors, John Wiley, 2008.

[4] Shigley, J. E. and Michke, C. R. "Mechanical engineering design", eighth edition, 2008 (Tata McGraw Hill, New Delhi, India).

[5] R.E.PETERSON, "Stress Concentration Factor", third edition, 2011(A Wiley inter science publication).

[6] Dejan B. Momcliovic et.al, "Analysis and Failure Improvement of Shaft of Gear Motor in CRM Shop" International Journal of Engineering and Science Vol-3, Issue 4, pp. 17-24.

[7] Roark, R. J.; and Young, W. C. "Formulas for Stress and Strain", Sixth edition, McGraw-Hill, 2006.

[8] H. M. Tlilan, A. S. Al-Shyyab, A. M. Jawarneh, A. K. Ababneh, "Strain concentration factor of circumferentially V-notched cylindrical bars under static tension". Journal of Mechanics, vol. 24 (4), 419-427, 2008.

[9] M. M. Leven and M. M. Frocht, "Stress-concentration factors for single notch in flat bar in pure and central bending," J. Appl. Mechanics, vol. 74, pp. 560-561. 1952.

[10] G. Meneghetti, C. Guzzella, B. Atzori, The peak stress method combined with 3D finite element models for fatigue assessment of toe and root cracking insteel welded joints subjected to axial of bending loading, Fatigue Fract. Eng. Mater. Struct. 37 (2014) $722-739$.

[11] C. Mattheck, Teacher tree: the evolution of notch shape optimization from complex to simple, Eng. Fract. Mech. 73 (12) (2006) $1732-1742$

[12] C. Mattheck, Design in Nature: Learning from Trees, Springer, 1998.

[13] C. Mattheck, S. Burkhardt, A new method of structural shape optimization based on biological growth, Int. J. Fatigue 12 (3) (1990) $185-190$.

[14] Grodzinski, P., "Investigations on shaft fillets," Engineering (London), Vol. 152,1941, pp. 321-331

[15] Mattheck, C., Erb, D., Bethge, K., and Begemann, U., "Three-dimensional shape optimization of a bar with a rectangular hole," Fatigue and Fracture of Engineering Materials and Structures, Vol. 15, No. 4, 1992, pp. 347-351

[16] Taylor, D., The Theory of Critical Distances: A New Perspective in Fracture, Mechanics, Elsevier, Oxford, UK, 2007.

[17] Waldman,W., Heller, M., and Chen, G. X. Optimal freeform shapes for shoulder fillets in flat plates under tension and bending. Int. J. Fatigue, 2001, 23, 509-523

[18] Francavilla, A., Ramakrishnan, C. V., and Zienkiewicz, O. C. Optimization of shape to minimize stress concentration. J. Strain Analysis, 1975, 10(2), 63-70. DOI: 10.1243/0309324V102063.

[19] Kristensen, E. S. and Madsen, N. F. On the optimum shape of fillets in plates cases subjected to multiple in plane loading cases. Int. J. Numer. Methods Eng., 1976, 10, 1007-1019.

[20] Bhavikatti, S. S. and Ramakrishnan, C. V. Optimum shape design of shoulder fillets in tension bars and T-heads. Int. J.Mech. Sci., 1979, 21(1), 29-39.

[21] Queau,J.P. and Trompette,P. H. Two-dimensional shape optimal design by the finite element method. Int. J. Number .Methods Eng., $1980,15,1603-1612$.

[22] Pedersen, P. and Laursen, C. L. Design for minimum stress concentration by finite element and linear programming's. Struct.Mech., 1982-83, 10(4), 375-391.

[23] Schnack, E. and Sporl, U. A mechanical dynamic programming algorithm for structure optimization. Int. J. Numer. Methods Eng., 1986, 23, 1985-2004. 


\section{AUTHOR PROFILE}

Er. Arjun A Abhyankar is pursing M. E. in Mechanical Design Engineering from Savitribai Phule, Pune University. He has completed B.E. from Nagpur University. He has presented three International conference papers in the field of Optimization. His areas of interest are Optimization, Strength of Materials and Automobile Engineering, Product design \& development.

Prof. Gaurav P Deshmukh is working in D Y Patil Institute of Engineering and Technology, Ambi, Pune as an Assistant Professor in the department of Mechanical Engineering. He received M.E. degree in Machine Design from Pune University and B.E degree from Aurangabad University. His areas of interest are Design, Mechanical Vibrations and Automobile Engineering.

Er.Vinit Raut is working in Vijay Transtech, Mumbai as Manager in the department of New Product Development. He received B.E degree from Kolhapur University. He has 12 years of experience in fields of new product development and quality. His areas of interest are Design, Quality Assurance \& Control, Value Engineering, and Automobile 